\title{
INSTITUTO FEDERAL DE EDUCAÇÃO, CIÊNCIA E TECNOLOGIA DE SÃO PAULO E O DIREITO A UMA ESCOLA PÚBLICA DE QUALIDADE: UM ESTUDO SOBRE O PERFIL DOS JOVENS ESTUDANTES INGRESSANTES NO ENSINO MÉDIO TÉCNICO INTEGRADO
}

\author{
D. S. SANTOS* E M. K. N. SANTOS \\ Instituto Federal de Educação, Ciência e Tecnologia de São Paulo \\ danielle.s.santos@gmail.com*
}

Artigo submetido em outubro/2014 e aceito em dezembro/2014

DOI: $10.15628 /$ rbept.2014.3483

\section{RESUMO}

O presente trabalho configura-se a partir dos preceitos adotados na criação e expansão dos Institutos Federais de Educação, Ciência e Tecnologia no que diz respeito à democratização do acesso à educação pública de qualidade. Intentou-se observar os limites práticos desta democratização a partir de análise de dados dos processos seletivos para os cursos técnicos integrados ao ensino médio da instituição no campus São Paulo. Para tanto, foram consideradas as políticas públicas acionadas nos atuais processos de seleção, buscando-se traçar um perfil dos jovens ingressantes nos cursos técnicos integrados com vistas a uma análise dos critérios sociais, econômicos e culturais que impactam no acesso ou não a esta rede de ensino e em que medida o fazem. Nossa indagação se pauta na caracterização deste perfil diante das demandas de atendimento preconizadas pelas políticas de criação dos Institutos Federais.

PALAVRAS-CHAVE: Institutos Federais, democratização, perfil de ingressantes.

\section{INSTITUTE OF EDUCATION FEDERAL, SCIENCE AND TECHNOLOGY OF SÃO PAULO AND THE RIGHT TO QUALITY PUBLIC SCHOOL: A STUDY ON THE PROFILE OF YOUNG STUDENTS IN HIGH SCHOOL ENTERING INTEGRATED TECHNICIAN}

\begin{abstract}
The present work sets up from the principles adopted in the creation and expansion of the Federal Institutes of Education, Science and Technology regards to the democratization of access to quality public education. The intention was to observe the practical limits of this democratization through data analysis of the selection process at São Paulo campus for the technical courses integrated with high school. To this end, were considered
\end{abstract}

the public policies triggered in the selection process, seeking to draw a profile of the incoming youths of the integrated technical courses aimed to analyze the social, economic and cultural criteria that impact the access or not to this school system and at what level it do. Our investigation is guided by the characterization of this profile facing the desired demands by the public policies at the creation of the Federal Institutes.

KEYWORDS: Federal institutes, democratization, entering profile. 


\section{INTRODUÇÃO}

No Brasil, assistimos nas últimas décadas a uma expansão da oferta de vagas nos sistemas de ensino, em todos os níveis e modalidades e, especificamente no que diz respeito à escola para jovens e para adultos, uma ampliação considerável das oportunidades de acesso ao Ensino Médio, ao ensino técnico, tecnológico e superior. Os investimentos realizados neste campo aparecem, no discurso governamental, justificados em boa parte por um duplo diagnóstico: a identificação de uma lacuna de investimentos nesta área durante os anos de vigência do FUNDEF (que privilegiou a ação governamental focada no ensino fundamental) e a crença numa espécie de insuficiência de qualificação e de formação da mão de obra jovem e adulta brasileiras que traria entraves significativos ao desenvolvimento econômico do país.

Além disso, o discurso governamental identifica na garantia do acesso a tais oportunidades escolares um mecanismo líquido e certo para a melhoria das condições de vida da população que, uma vez mais escolarizada e/ou melhor escolarizada, encontraria postos de trabalho menos degradantes e com maior retorno financeiro, transpondo as limitações sociais e econômicas de origem e ascendendo em termos de consumo e renda.

Para concretizar essa diretriz de investimento na expansão das oportunidades de escolarização para jovens e adultos, uma das estratégias mais centrais do governo federal foi a criação e expansão dos Institutos Federais de Educação, Ciência e Tecnologia no Brasil. De acordo com Daros (2013):

Os institutos federais têm a finalidade de desenvolver a Educação Profissional e Tecnológica em todos os seus níveis e modalidades, formando cidadãos para atuar nos diversos ramos da economia com ênfase no desenvolvimento socioeconômico local, regional e nacional. Além disso, os institutos federais visam:

- desenvolver a Educação Profissional e Tecnológica como processo educativo e investigativo para que a criação e as adaptações de soluções técnicas e tecnológicas necessárias às demandas sociais e regionais sejam consideradas; - promover a integração e a verticalização da educação básica à Educação Profissional e Educação Superior, possibilitando a otimização de quadros de pessoal e recursos de gestão;

- orientar sua oferta de cursos em benefício da consolidação e fortalecimento dos arranjos produtivos, sociais e culturais locais. (DAROS, 2013, p.37-38)

Com a Lei no 11.892 , de 29/12/2008, os institutos federais são equiparados às universidades federais ganhando "natureza jurídica de autarquia, detentoras de autonomia administrativa, patrimonial, financeira, didático-pedagógica e disciplinar". A oferta dos cursos é assim regulamentada:

Art. 70. Observadas as finalidades e características definidas no art. 60 desta Lei, são objetivos dos Institutos Federais:

I - ministrar educação profissional técnica de nível médio, prioritariamente na forma de cursos integrados, para os concluintes do ensino fundamental e para o público da educação de jovens e adultos;

II - ministrar cursos de formação inicial e continuada de trabalhadores, objetivando a capacitação, o aperfeiçoamento, a especialização e a atualização de 
profissionais, em todos os níveis de escolaridade, nas áreas da educação profissional e tecnológica;

III - realizar pesquisas aplicadas, estimulando o desenvolvimento de soluções técnicas e tecnológicas, estendendo seus benefícios à comunidade;

IV - desenvolver atividades de extensão de acordo com os princípios e finalidades da educação profissional e tecnológica, em articulação com o mundo do trabalho e os segmentos sociais, e com ênfase na produção, desenvolvimento e difusão de conhecimentos científicos e tecnológicos;

$\mathrm{V}$ - estimular e apoiar processos educativos que levem à geração de trabalho e renda e à emancipação do cidadão na perspectiva do desenvolvimento socioeconômico local e regional; e

VI - ministrar em nível de educação superior:

Art. 8‥ No desenvolvimento da sua ação acadêmica, o Instituto Federal, em cada exercício, deverá garantir o mínimo de $50 \%$ (cinquenta por cento) de suas vagas para atender aos objetivos definidos no inciso I do caput do art. 70 desta Lei, e o mínimo de $20 \%$ (vinte \%) de suas vagas para atender ao previsto na alínea b do inciso VI do caput do citado art. 7ㅇ.

Conforme o texto da Lei, fica claro a prioridade que é dada para a oferta de cursos na modalidade integrada ao ensino médio, como ressalta Daros:

É importante ressaltar que dentre os objetivos previstos pela Lei no 11.892, de 29 de dezembro de 2008 , os institutos federais devem ofertar $50 \%$ de suas vagas para a Educação Profissional Técnica de nível médio, prioritariamente na forma integrada, para os concluintes do ensino fundamental e para o público da Educação de Jovens e Adultos. (DAROS, 2013, p. 38-39)

A partir desta constatação, concentramos nosso estudo justamente na modalidade apresentada por Daros. Mas esta não é a única razão para a nossa escolha: há, de nossa parte, interesse específico em compreender nossa própria inserção na Diretoria de Educação Básica do IFSP, que tem, dentre suas diferentes competências, a atribuição de articular as políticas de Educação Básica, de promover a interlocução entre o Ministério da Educação e o IFSP quanto às essas políticas e de orientar e apoiar a execução dos regulamentos e normas no âmbito dos cursos da Educação Básica.

Julgamos a criação dos Institutos Federais um importante avanço da ampliação da oferta de vagas em um modelo de escola pública reconhecido por boa parte da sociedade como uma "escola de qualidade". No entanto, identificamos que, apesar desta ampliação, a oferta de vagas ainda é menor que a demanda de estudantes que as buscam. Nesse sentido, prevalece, na rede de ensino federal (e nos IFs), uma lógica específica de seleção, por meio de exame de saberes em provas de múltipla escolha ou por meio do SISU. Nossa hipótese de trabalho é que este processo de seleção, além de um mecanismo formal de ajuste da demanda por vagas ao número de oportunidades existentes, é também uma importe chave para refletirmos sobre a constituição do perfil dos alunos do Instituto Federal de Educação, Ciência e Tecnologia de São Paulo (IFSP).

À semelhança do que já se identificou no campo de pesquisas sobre o ensino superior, o processo de seleção que possibilita (ou não) o ingresso dos estudantes em vagas de cursos superiores reconhecidos como de melhor qualidade demarca e reproduz uma determinada 
herança, um certo tipo de capital cultural que está além da checagem do domínio de certos conteúdos apresentados nos mapas curriculares do ensino médio.

No texto de Pacheco (2011) "Os Institutos Federais - Uma revolução na educação profissional e tecnológica", encontramos uma posição específica a respeito do caráter transformador da criação e expansão dessas instituições. O Ministério da Educação assinala que os IFs são parte de uma política educacional que, além de se contrapor ao modelo neoliberal abriu "oportuni-dades para milhões de jovens e adultos da classe trabalhadora". A concepção de uma escola transformadora também está presente no documento "Um novo modelo em educação profissional e tecnológica - concepção e diretrizes":

O Instituto Federal aponta para um novo tipo de instituição identificada e comprometida com o projeto de sociedade em curso no país. Representa, portanto, um salto qualitativo em uma caminhada singular, prestes a completar cem anos. Trata-se de um projeto progressista que entende a educação como compromisso de transformação e de enriquecimento de conhecimentos objetivos capazes de modificar a vida social e de atribuir-lhe maior sentido e alcance no conjunto da experiência humana, proposta incompatível com uma visão conservadora de sociedade. Trata-se, portanto, de uma estratégia de ação política e de transformação social. (BRASIL, MEC, 2010, p.19)

Seria razoável supor, assim, que a reprodução das posições de classe identificadas nos mecanismos de seleção para o ensino superior, tradicionalmente identificadas como formas mais ou menos regulamentares para excluir as parcelas mais pobres e os jovens das classes trabalhadoras dos melhores cursos, nas instituições mais reconhecidas, seriam mitigadas ou mesmo superadas a partir das ações propostas com a criação e expansão dos IFs.

De fato, a edição da Lei $n$ o $12.711 / 2012^{1}$ e sua adoção por praticamente todos os IFs, foram decisões de política pública que pretendiam criar mecanismos de discriminação positiva capazes de alterar a lógica em funcionamento nos processos seletivos e diversificar o acesso, democratizando o ingresso a partir da inclusão de grupos historicamente invisíveis em instituições deste tipo.

Como se organizaram essas ações no IFSP e quais têm sido seus efetivos impactos na correção das desigualdades de acesso e permanência dos jovens à forma de ensino médio integrado? Como a análise dos processos seletivos realizados nos últimos anos evidencia (ou não) o sucesso da aposta numa transformação democratizadora proposta para essa modalidade de escolarização dos jovens no IFSP?

Em nossa exposição, propomos, incialmente, dialogar com o trabalho de Bandera (2011) que investigou como o processo seletivo - Vestibulinho - "produz uma rigorosa seleção de jovens, majoritariamente meninos brancos ou amarelos oriundos das "frações de classes" médias, aptos à

\footnotetext{
1 A Lei no 12.711/2012 estabelece que no mínimo 50\% das vagas das instituições federais de educação superior deverão ser destinadas para estudantes que tenham cursado integralmente o ensino médio na rede pública, com implementação progressiva no prazo de quatro anos, $25 \%$ a cada ano; no mínimo $50 \%$ das vagas do ensino médio, técnico federal, deverão ser destinados a estudantes que cursaram integralmente o ensino fundamental na rede pública, com implementação progressiva no prazo de quatro anos, 25\% a cada ano; e por fim, as vagas reservadas deverão ser preenchidas, por curso e turno, no mínimo na proporção de pretos, pardos e indígenas do último censo demográfico.
} 
rigorosa ação pedagógica da instituição". Sua pesquisa foi realizada em 2009 com jovens do 3 ano que ingressaram em 2006 nos cursos de nível médio do campus São Paulo. ${ }^{2}$ Neste contexto, o trabalho do autor aponta para as seguintes características do perfil dos estudantes:

Os jovens alunos da Federal são constantemente chamados à ordem pelas incessantes narrativas familiares que produzem o lastro emocional e moral que sustenta o enorme investimento na conquista da cultura. Essa narrativa familiar, [...] foi produzida a partir de um esteio objetivo que sustenta a posição social de determinadas frações das classes médias paulistanas. (BANDERA, 2011, p.21)

Destacamos no texto do autor o fato de que se trata de escola pública que "não consegue democratizar o acesso ao ensino de qualidade". Tendo essa questão como referência, tomamos aqui a concepção da política de criação e expansão dos Institutos Federais de Educação, Ciência e Tecnologia no Brasil. Queremos com isso, colocar a discussão sobre a eficácia desta política de educação profissional que pressupõe um projeto progressista comprometido com a transformação social que se contrapõe a uma "visão conservadora de sociedade". Se por um lado dimensionar a eficácia desta estratégia política, nos parece uma tarefa por demais complexa, por outro lado, acreditamos ser fundamental verificarmos em que medida o projeto de criação dos IF avançaram na superação do modelo de escola descrito por Bandera.

\section{PERFIL DOS JOVENS INGRESSANTES DO IFSP}

Uma síntese do perfil dos estudantes do IFSP ingressantes no ano de 2006 pode ser assim resumido: Origem social a maioria são de família de frações da classe média, o número de mães e pais com nível superior completo e pós-graduação eram $53 \%$ e $51 \%$ respectivamente, $70 \%$ estudaram em escolas particulares ou majoritariamente nestas, $78 \%$ são do sexo masculino, $60 \%$ se autodeclararam brancos.

A partir dos dados dos 283 questionários socioeconômico preenchidos pelos estudantes ingressantes no IFSP no primeiro semestre de 2015, apresentaremos dados, com base nos quais acreditamos ser possível caracterizar o atual perfil dos estudantes. Questões como: Renda, escolarização dos pais, raça/etnia, sexo, e escola de origem são os aspectos que sustentaram inicialmente a caracterização dos estudantes do IFSP.

\subsection{Da classe econômica}

Para definição de classe, a partir do fator renda familiar, utilizamos os critérios estabelecidos pela Fundação Getúlio Vargas, conforme quadro abaixo:

\footnotetext{
2 O campus São Paulo foi criado pelo Decreto no 7.566, de 23/9/1909, hoje faz parte do IFSP, sendo o maior e mais antigo campus. Notoriamente é considerado umas das melhores escolas públicas da capital paulista, dado que se confirma pela procura e concorrência dos cursos nos processos de seleção.
} 
Tabela 1: Classe social por renda em Reais

\begin{tabular}{c|c}
\hline Classe & Renda em Reais \\
\hline A & Acima de $R \$ 9.745,00$ \\
$B$ & De $R \$ 7.475,00$ a $R \$ 9.745,00$ \\
C & De $R \$ 1.734$ a $R \$ 7.475,00$ \\
$D$ & De $R \$ 1.085,00$ a $R \$ 1.734,00$ \\
E & De $R \$ 0,00$ a $R \$ 1.085,00$ \\
\hline
\end{tabular}

Fonte: Fundação Getúlio Vargas

Tabela 2: Renda familiar

\begin{tabular}{c|c|c}
\hline Em salários mínimos & Número & Percentual \\
\hline Até $R \$ 362,00$ reais (Até meio salário) & 2 & 1 \\
Até $R \$ 724,00$ reais (Até 1 salário) & 7 & 2 \\
De $R \$ 1.448,01$ a $R \$ 2.172,00$ reais (De 2 a 3 salários) & 32 & 11 \\
De $R \$ 2.172,01$ a $R \$ 3.620,00$ reais (De 3 a 5 salários) & 64 & 23 \\
De $R \$ 3.620,01$ a $R \$ 7.240,00$ reais (De 5 a 10 salários) & 90 & 32 \\
De $R \$ 7.240,01$ a $R \$ 14.480,00$ reais (De 10 a 20 salários) & 45 & 16 \\
De $R \$ 724,01$ a $R \$ 1.448,00$ reais (De 1 a 2 salários) & 31 & 11 \\
Mais de $R \$ 14.480,00$ reais (Mais de 20 salários) & 12 & 4 \\
Total Geral & 283 & 100 \\
\hline
\end{tabular}

Organizado pelas pesquisadoras

No que diz respeito à origem social dos estudantes, os dados revelam que a maioria são oriundos de famílias das classes C, B e A. Entre as produções acadêmicas encontramos vários estudos que apontam para uma relação, não direta, mas mediada pela relação origem social e sucesso escolar; entre eles podemos destacar os estudos de Bourdieu e Passeron. Conforme Santos 2010, estes autores nos mostram que a escola transmite e avalia uma cultura que não é socialmente neutra. Assim, as crianças que receberam na sua família e na sua classe social um "Capital Cultural" que a escola privilegia, têm mais chances de serem alunos bem-sucedidos na vida escolar.

\subsection{Da escolarização dos pais}

Tabela 3: Escolarização dos pais

\begin{tabular}{c|c|c|c|c}
\hline \multirow{2}{*}{ Nível de escolarização } & \multicolumn{2}{|c|}{ Pai } & \multicolumn{2}{c}{ Mãe } \\
\cline { 2 - 5 } & Número & Percentual & Número & Percentual \\
\hline Ensino Fundamental completo & 6 & 2 & 11 & 4 \\
Ensino Fundamental incompleto & 8 & 3 & 4 & 1 \\
Ensino Fundamental incompleto & 17 & 6 & 7 & 2 \\
Ensino Médio (antigo 2o grau) & 65 & 23 & 75 & 27 \\
Ensino Médio (antigo 2o grau) Incompleto & 10 & 3 & 9 & 3 \\
Ensino Superior & 83 & 29 & 107 & 39 \\
Ensino Superior Incompleto & 39 & 14 & 25 & 9 \\
Não estudou & 1 & 0 & 0 & 0 \\
Não sei & 10 & 4 & 5 & 2 \\
Pós-graduação & 44 & 16 & 40 & 14 \\
Total Geral & 283 & 100 & 283 & 100 \\
\hline
\end{tabular}

Organizado pelas pesquisadoras

Apesar do nível de escolarização dos pais não ser por si só um fator determinante para o sucesso escolar, aqui entendido como aprovação no processo seletivo do IFSP, podemos observar 
um alto índice de escolarização de nível superior entre os pais dos estudantes. Tal percepção pode ter explicação, por um lado, nos estudos que apontam que as famílias com maior nível de escolarização tendem a acompanhar e ajudar mais nas atividades escolares das crianças. Por outro, é altamente sugestivo o recente estudo de Costa al. et. (2013) sobre a "problemática da distribuição de oportunidades entre as escolas públicas", segundo o qual, na busca pelas melhores escolas públicas, pais com escolarização mais altas tendem a fazer escolhas mais subsidiadas que os pais com menos escolarização. Para os autores, a diferença, neste caso, está nas redes de contato das famílias.

\subsection{Da origem escolar}

Tabela 4: Origem escolar

\begin{tabular}{c|c|c}
\hline Origem escolar & Número & Percentual \\
\hline A maior parte do tempo em escola particular & 17 & 6 \\
A maior parte do tempo em escola pública & 16 & 6 \\
Integralmente em escola particular & 167 & 59 \\
Integralmente em escola pública & 83 & 29 \\
Total Geral & 283 & 100 \\
\hline
\end{tabular}

Organizado pelas pesquisadoras

O discurso midiático, popular e até mesmo acadêmico tem apontado para uma desigualdade entre escolas públicas e privadas. Tal desigualdade pode justificar a leitura da Tabela 4 que aponta que $59 \%$ dos alunos que ingressam no IFSP são oriundos de escolas particulares. Outro dado a ser considerado é o "ranking" de classificação das escolas elaborado a partir das notas dos alunos. Segundo dados do Enem de 2013, das cinquenta escolas com as melhore notas quarenta e oito são privadas e apenas duas são da Rede Federal ${ }^{3}$. Entretanto, apesar destas constatações é importante salientar que essas desigualdades não ocorrem apenas pelo dualismo entre escola da rede pública e rede privada, mas também entre escolas de mesmas redes.

\subsection{Dos meninos e das meninas}

Tabela 5: Sexo

\begin{tabular}{c|c|c}
\hline Sexo & Número & Percentual \\
\hline Feminino & 79 & 28 \\
Masculino & 204 & 72 \\
Total Geral & 283 & 100 \\
\hline
\end{tabular}

Organizado pelas pesquisadoras

Um fator importante a ser considerado, no caso dos cursos ofertados pela então Escola Técnica, é a tradição que se consolidou em torno desses cursos. Em meio ao simbolismo de um centro de educação tecnológica e tudo que isto acarreta em termos de visão e concepções de trabalho, o que se observa é a não superação por completo da premissa de exclusão feminina dos processos de escolarização quando falamos de áreas tradicionalmente masculinizadas, como é o caso dos cursos técnicos integrados ao Ensino Médio ofertados no câmpus São Paulo - Informática, Eletrotécnica, Eletrônica e Mecânica.

\footnotetext{
${ }^{3}$ Fonte: Jornal Folha de São Paulo de 22 de dezembro de 2014.
} 
Assim, em se tratando de uma educação técnico-profissional, ou seja, voltada também para a profissionalização, e apesar de dados que afirmam que no Brasil a escolarização entre as mulheres é maior que entre os homens, a predominância de meninos nos cursos do IFSP é um indicativo importante da continuidade da divisão sexual do trabalho, como que ciência e tecnologia ainda pertencendo ao domínio masculino.

\subsection{Das questões de raça/etnia}

Tabela 6: Auto declaração de Raça/Etnia

\begin{tabular}{c|c|c}
\hline Raça/Etnia & Total & Percentual \\
\hline Amarela & 36 & 13 \\
Branca & 157 & 56 \\
Indígena & 1 & 0 \\
Parda & 66 & 23 \\
Prefiro não declarar & 9 & 3 \\
Preta & 14 & 5 \\
Total Geral & 283 & 100 \\
\hline
\end{tabular}

Organizado pelas pesquisadoras

Tabela 7: Auto declaração por sexo

\begin{tabular}{c|c|c|c|c}
\hline \multirow{2}{*}{$\begin{array}{c}\text { Auto declaração } \\
\text { Raça/Etnia }\end{array}$} & Total & Percentual & Total & Percentual \\
\hline Amarela & 9 & 12 & 27 & 13 \\
Branca & 39 & 49 & 118 & 58 \\
Indígena & 1 & 1 & 0 & 0 \\
Parda & 22 & 28 & 44 & 22 \\
Prefiro não declarar & 3 & 4 & 6 & 3 \\
Preta & 5 & 6 & 9 & 4 \\
Total Geral & 79 & 100 & 204 & 100 \\
\hline \multicolumn{4}{|c}{}
\end{tabular}

Faz-se importante frisar que, no quesito raça/etnia, os dados são apresentados a partir da auto declaração. A Tabela 7 aponta para uma minoria negra (pretos e pardos) de estudantes que ingressam no IFSP nos cursos integrados, um cenário pouco distinto do que ocorre na imensa maioria das universidades públicas brasileiras. Disto decorre uma análise necessária que implica considerar questões de ordem de classe que se imbricam com as questões de gênero e também de raça. Como bem afirma Cunha Jr (1992), classe e raça "são duas faces entrelaçadas e ambas moldam a nossa realidade". É importante lembrar que aqui utilizamos raça enquanto conceito sociológico que define, para além de diferenças fenotípicas, toda uma gama de relações historicamente delimitadas em nossa sociedade.

Neste sentido, ressaltamos que a já referida Lei de Cotas estabelece, além do quesito renda, a categoria raça para o ingresso nos Institutos Federais. Isto se justifica, em nosso entender, na evidência já constatada da diferenciação dos níveis sociais e econômicos entre diferentes grupos raciais no Brasil. Além disso, é preciso considerar o próprio arranjo dito democrático das 
instituições de ensino, tendo em vista o caráter excludente dos processos de seleção que perpassavam e ainda perpassam, para além dos critérios sociais, pelos fatores da identidade cultural, o que nos permite inserir a categoria raça como fator de inclusão/exclusão. Estamos falando de índices que comprovam um menor acesso a educação e também uma menor permanência na escola do estudante negro. Lembremos que o racismo institucional fere diretamente o acesso à cidadania, lugar político no qual a educação escolar exerce um importante papel.

\section{CONSIDERAÇÕES FINAIS}

A partir dos dados dos questionários verificamos que a maioria dos jovens aprovados são oriundos das frações de classe média. Como vimos anteriormente, apesar de não serem determinantes, as condições econômicas podem prejudicar ou favorecer o desempenho escolar. Conforme Santos, "as diferenças nas condições de vida das crianças, ao se traduzirem em impeditivos ou facilitadores de tais situações, lugares, momentos e mecanismos trarão, assim, diferentes impactos na relação entre sucesso e fracasso escolar" (Santos, 2010, p.41).

Ainda segundo os dados, $59 \%$ dos ingressantes estudaram integralmente escolas particulares o ensino fundamental, $72 \%$ são meninos, $56 \%$ do total dos estudantes autodeclaramse brancos, $13 \%$ amarelos, apenas $14 \%$ se autodeclaram pretos e $23 \%$ pardos. Entre os estudantes do sexo masculino apenas $4 \%$ se autodeclaram pretos. Em contraposição, o relatório apresentado pelo MEC no primeiro aniversário da Lei $n=12.711 / 2012$, apontava que $83 \%$ dos institutos federais de educação, ciência e tecnologia já atingiram a meta, prevista para 2016, de reserva de vagas mínima de $50 \%$ para alunos oriundos de escolas públicas. Contudo, apesar da referida Lei lançarse no cenário educacional como uma importante política de inclusão social, constatamos que muito ainda temos que avançar no sentido de incluir em nossas escolas essa parcela da população que foi historicamente excluída e marginalizada.

A título de conclusão podemos dizer que em relação ao perfil identificado por Bandera (2011) os dados levantados, neste trabalho, não apontam para mudanças significativas no perfil dos estudantes. Ao apresentarmos tais apontamentos, o que estamos procurando realizar é uma discussão sobe os avanços e limites da política de criação dos IFs no que se refere ao compromisso efetivo com a democratização do acesso dos jovens da classe trabalhadora a este sistema de ensino. Assim sendo, concluímos que a democratização para essa modalidade de escolarização ainda é uma meta a ser alcançada.

Ressaltamos que a delimitação do nosso trabalho nos impedirá de, quer por ingenuidade, quer por ambição, traçar um diagnóstico completo acerca da eficácia, do sucesso ou da potência do caráter transformador da criação e expansão dos IFs. Responder a uma questão como esta demandará, certamente, um estudo de escopo infinitamente maior.

\section{REFERÊNCIAS}

1. BANDERA, Nicolau Dela. "Esforçados" e "talentosos": A produção do sucesso escolar na Escola Técnica Federal de São Paulo. São Paulo, 2011. Dissertação de Mestrado em SociologiaUniversidade de São Paulo, 2011. 
2. BRASIL. Lei n. 12.711 de 29 de agosto de 2012. Dispõe sobre o ingresso nas universidades federais e nas instituições federais de ensino técnico de nível médio e dá outras providências. Diário Oficial [da] República Federativa do Brasil, 30 ago. 2012.

3. BRASIL. Ministério da Educação. Instituto Federal de Educação, Ciência e Tecnologia um novo modelo em educação profissional e tecnológica- concepção e diretrizes. Brasília, 2010. Disponível em http://portal.mec.gov.br/dmdocuments/livreto_institutos.pdf. Acesso em 06 de junho de 2015.

4. __ Lei n. 11.892 de 29 de dezembro de 2008. Institui a Rede Federal de Educação Profissional, Científica e Tecnológica, cria os Institutos Federais de Educação, Ciência e Tecnologia, e dá outras providências. Diário Oficial [da] República Federativa do Brasil, 30 dez. 2008.

5. COSTA, Marcio et al. Oportunidades e escolhas - Famílias e escolas em um sistema desigual. In: Família \& Escola - Novas perspectivas de análise, NOGUEIRA, Maria Alice. ROMANELLI, Geraldo. ZAGO, Nadir. (Orgs). Editora Vozes, 2013. pp. $131-196$.

6. CUNHA JR, Henrique. Textos para o movimento negro. São Paulo: Edicon, 1992.

7. DAROS, Michelli Aparecida. O Instituto Federal de Educação, Ciência e Tecnologia de São Paulo - IFSP, A Evasão escolar e a atuação do serviço social: uma experiência em construção (20082013). Dissertação de mestrado, estudos de pós-graduação em Serviço Social da Pontifícia Universidade Católica de São Paulo, 2013.

8. PACHECO, Eliezer. Os Institutos Federais - Uma revolução na educação profissional e tecnológica. São Paulo: Moderna, 2011.

9. SANTOS, Danielle de Sousa. Uma análise do aspecto educacional do Programa Bolsa Família na União da Vila Nova/Vila Nair, bairro do município de São Paulo. Dissertação de mestrado, Programa de Estudos Pós-Graduados em Educação: História, Política, Sociedade, da Pontifícia Universidade Católica de São Paulo, 2010.

10. SOARES, Marcelo; FERNANDO, Rubens. Sudeste concentra 77 das 100 melhores escolas no Enem 2013. Folha de São Paulo, São Paulo, 22 dez. 2014. Disponível em http://www1.folha.uol.com.br/educacao/2014/12/1565990-sudeste-concentra-77-das-100melhores-escolas-no-enem-2013.shtml Acesso em 11 de mai. 2015 